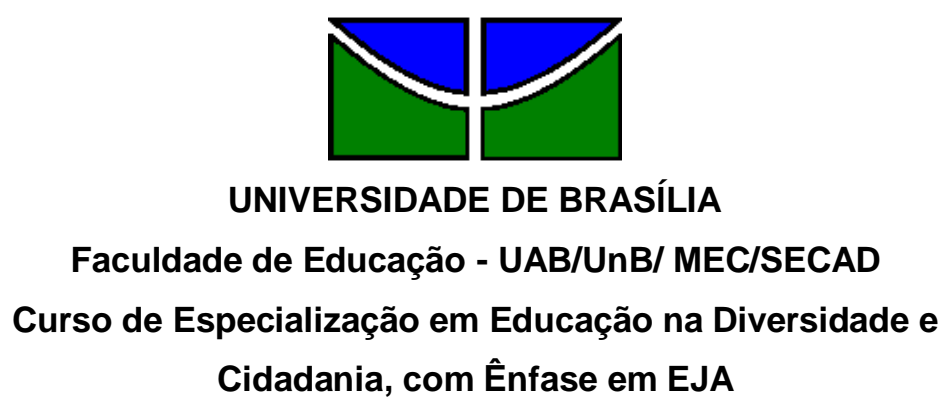

Emilia Marques Salsano

Gislane Pires Moreira de Assunção

Irlanda Aglae Correia Lima Borges

Lia Nani Costa Silveira

MEDIAÇÃO NA FORMAÇÃO DE LEITORES NA EJA 
UNIVERSIDADE DE BRASÍLIA

Faculdade de Educação - UAB/UnB/ MEC/SECAD

Curso de Especialização em Educação na Diversidade e Cidadania, com Ênfase em EJA

\title{
MEDIAÇÃO NA FORMAÇÃO DE LEITORES NA EJA
}

\author{
Emilia Marques Salsano \\ Gislane Pires Moreira de Assunção \\ Irlanda Aglae Correia Lima Borges \\ Lia Nani Costa Silveira
}

ANA AMÉRICA MAGALHÃES ÁVILA PAZ

DELIENE LOPES LEITE KOTZ

PROJETO DE INTERVENÇÃO LOCAL

BRASÍLIA, DF-JULHO/2010 
UNIVERSIDADE DE BRASÍLIA

Faculdade de Educação - UAB/UnB/ MEC/SECAD

Curso de Especialização em Educação na Diversidade e Cidadania, com Ênfase em EJA

Emilia Marques Salsano

Gislane Pires Moreira de Assunção

Irlanda Aglae Correia Lima Borges

Lia Nani Costa Silveira

\section{MEDIAÇÃO NA FORMAÇÃO DE LEITORES NA EJA}

Trabalho de conclusão do Curso de Especialização em Educação na Diversidade e Cidadania, com Ênfase em EJA, como parte dos requisitos necessários para obtenção do grau de Especialista na Educação de Jovens e Adultos

Ana América Magalhães Ávila Paz

Professora Doutoranda

Deliene Lopes Leite Kotz

Tutora Orientadora

Norma Lúcia Neris Queiroz.

Avaliador Externo

BRASÍLIA, DF Julho/2010 


\section{AGRADECIMENTOS}

Aos nossos educandos e educandas de Educação de Jovens e Adultos do CESAS, que nos transformam profissionalmente e que representam fonte contínua de aprendizado e desenvolvimento; e ao talentoso jornalista Ricardo Borges, que prontamente contribuiu com a ilustração de nosso projeto, representando a diversidade de nossa escola $e$ ilustrando o prazer da leitura em nosso sonhado laboratório, nossos sinceros agradecimentos. 


\section{RESUMO}

O presente Projeto de Intervenção Local propõe-se a promover situações diárias de aprendizagem favoráveis à leitura e à produção de textos em sala de aula; tornar a Biblioteca um ambiente mais atrativo e estimulante para a prática da leitura, criando nela um espaço privilegiado chamado Laboratório de Leitura. Aliado ao trabalho feito em sala, às visitas à Biblioteca Paulo Freire e ao Laboratório de Leitura, integrar a Comunidade de Trabalho/Aprendizagem em rede na Diversidade - CTARD torna-se imprescindível para a consolidação da transdisciplinaridade, uma vez que o estudante, adquirindo o entusiasmo permanente pela leitura, atuará de forma vigorosa, crítica e transformadora nas redes sociais. Em uma cultura basicamente marcada pela escrita, ter o domínio da leitura é poder desenvolver a capacidade de compreender melhor o meio em que se vive e ter mais autonomia diante dos desafios no mundo do trabalho. O despertar, a motivação e os estímulos para a aquisição do hábito da leitura e a posterior continuidade dessa prática passam pela intervenção do professor, mediador desse processo, que poderá ter melhor resultado em um ambiente apropriado e agradável.

Palavras- chave: Educação de Jovens e Adultos - leitura - Laboratório de leitura 


\section{SUMÁRIO}

1. Dados de identificação dos proponentes............................................................. 07

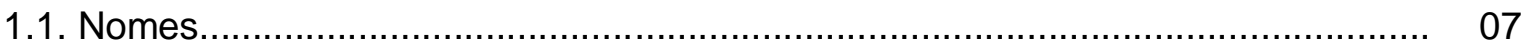

1.2. Turma

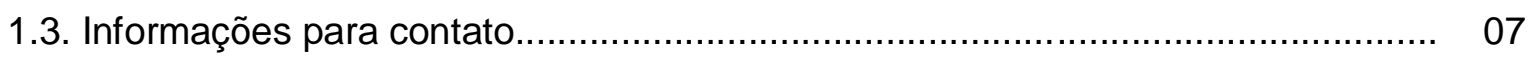

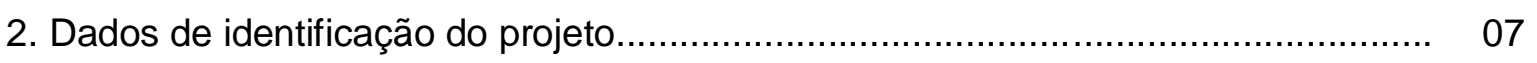

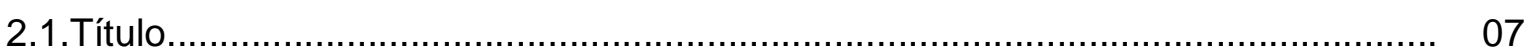

2.2. Área de abrangência............................................................................. 07

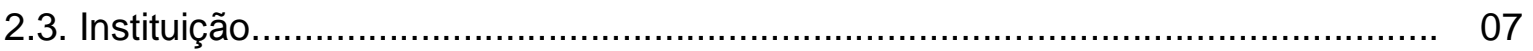

2.4. Público ao qual se destina............................................................................. 08

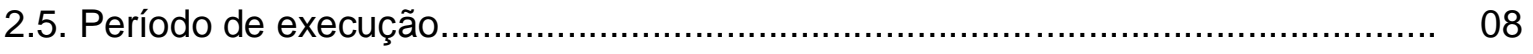

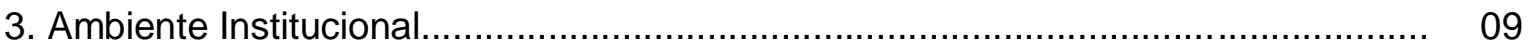

4. Justificativa e caracterização do problema....................................................... 11

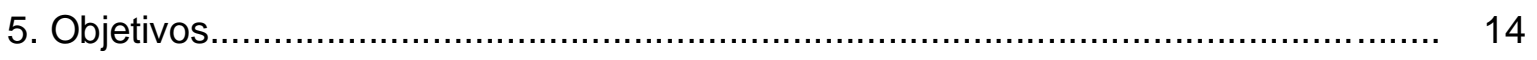

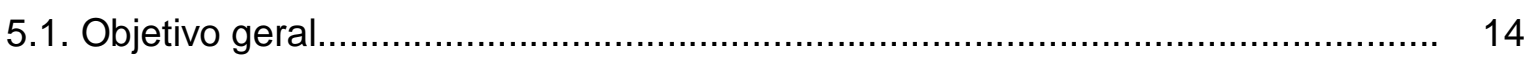

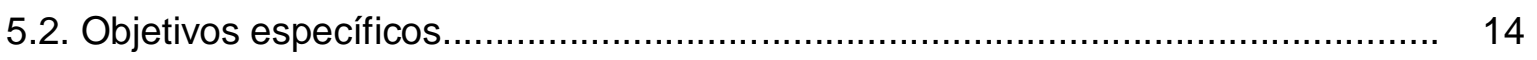

6. Atividades/responsabilidades...................................................................... 15

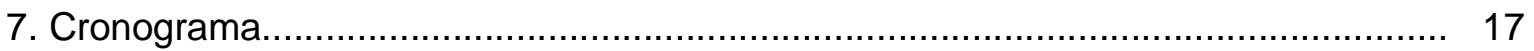

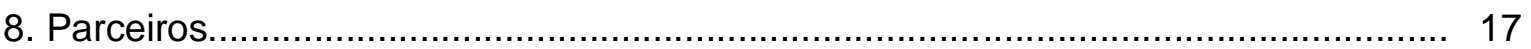

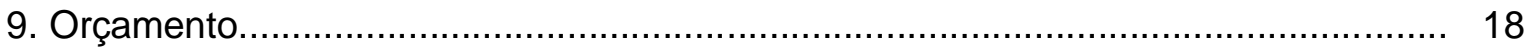

10. Acompanhamento e avaliação . .............................................................. 19

10.1. Instrumentos de acompanhamento............................................................ 19

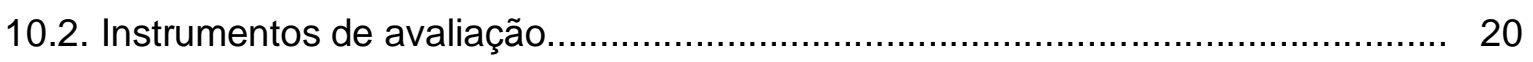

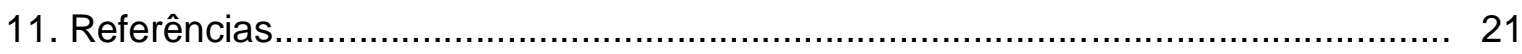

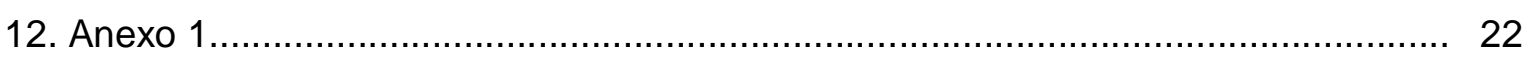

13. Anexo 2 
1- Dados de identificação do(s) proponente(s)

1.1-Nome(s)

Emilia Marques Salsano

Gislane Pires Moreira de Assunção

Irlanda Aglae Correia Lima Borges

Lia Nani Costa Silveira

\section{2-Turma: B}

\section{3- Informações para contato}

Telefone(s): (61) 9815-8801

E-mail: emiliasalsano@gmail.com

(61) $8513-6794$

gislanepmoreira@gmail.com

(61) $9219-0972$

iaglae@gmail.com

(61) $8165-0019$

liananics@gmail.com

\section{2- Dados de identificação do projeto}

\section{1- Título}

MEDIAÇÃO NA FORMAÇÃO DE LEITORES NA EJA

\section{2- Área de abrangência}

Local

\section{3- Instituição}

Nome

Centro de Educação de Jovens e Adultos da Asa Sul - CESAS

Endereço

SGAS 602, Área Especial, Projeção "D" - Brasília-DF 
Instância institucional de decisão

Governo do Distrito Federal, Secretaria de Estado de Educação, Conselho de Educação do

Distrito Federal, Conselho Escolar do Centro de Educação de Jovens e Adultos - CESAS.

\section{4- Público ao qual se destina}

Educandos do $3^{0}$ segmento (equivalentes ao ensino médio) da Educação de Jovens e Adultos (EJA) do Centro de Educação de Jovens e Adultos da Asa Sul (CESAS) no Distrito Federal.

\section{5- Período de execução}

Início: agosto/2010

Término: dezembro/2010 


\section{3- Ambiente institucional}

O Centro de Educação de Jovens e Adultos - CESAS está localizado no SGAS 602, na via L2 Sul, Asa Sul, bem próximo ao centro do Plano Piloto de Brasília-DF e tem um significado especial para a EJA, que só pode ser entendido depois de uma breve reflexão sobre história da própria educação de jovens e adultos no Brasil.

Desde o período colonial os jesuítas, religiosos da Companhia de Jesus que chegaram ao Brasil em 1549, embora mais voltados para a instrução erudita e religiosa dos filhos dos colonos, já se preocupavam em ensinar e catequizar crianças, jovens e adultos colonos e índios. Assim, foi o caráter elitista e excludente que marcou a educação no Brasil, incapaz de propiciar o letramento de toda a sociedade até o advento da industrialização na década de 1930. Foi nessa década que se delineou o perfil do que viria a ser a EJA atual, com a criação do Ministério da Educação e Saúde Pública, em 1930, e com a promulgação da Constituição de 1934, determinando a oferta de ensino obrigatório e gratuito para todos. Não cabe aqui relatar minuciosamente todas as ações voltadas para educação de jovens e adultos, mas vale destacar a Campanha de Educação de Adolescentes e Adultos - CEAA, que vigorou de 1947 até 1963, a criação do Movimento Brasileiro de Alfabetização MOBRAL, em 1967, e a institucionalização do Ensino Supletivo, em 1971, pela Lei 5.692, através da qual se pretendia "recuperar o atraso dos que não puderam realizar sua escolarização na época adequada" e "complementar o êxito empolgante do MOBRAL" (HADDAD \& DI PIERRO, 2000, p. 117). Conforme propunha a Lei os Conselhos Estaduais de Educação regulamentariam o ensino supletivo em seus estados.

Dessa forma nascia o ensino supletivo, com quatro funções básicas: suplência, suprimento, aprendizagem e qualificação. Vale lembrar que nos idos da década de 1970 o Brasil vivia o auge do regime militar e do "milagre econômico" quando o discurso político intencionava "corrigir as desigualdades [...] e assegurar a coesão das classes sociais" (idem, p. 118). Apesar da centralização federal, houve certa dispersão dentro dessa modalidade de ensino: enquanto os programas federais eram voltados para a suplência e referiam-se ao aperfeiçoamento dos exames, do ensino personalizado apoiado em módulos e do ensino a distancia, no âmbito municipal as ações resumiam-se a programas de alfabetização.

Dentro desse cenário, através do Parecer no 19/75-CEDF, foi criado o Centro de Ensino Supletivo da Asa Sul - CESAS, pondo em prática todos os programas relativos à modalidade de suplência - o mesmo que substituição compensatória do ensino regular com certificação de ensino dos então $1^{\circ}$ e $2^{\circ}$ Graus.

As décadas de 1980 e 1990 foram marcadas por rupturas e conquistas no âmbito da educação de jovens e adultos, mesmo depois de ganhos inovadores da sociedade civil. A 
redemocratização do país e a promulgação da Constituição Cidadã de 1988 garantiram para a educação brasileira, conquistas já consagradas universalmente, tais como "ensino fundamental, obrigatório e gratuito, inclusive para os que não tiveram acesso na idade própria" (art. 208, inciso I). Entretanto, as políticas educacionais nos anos 90, ao focalizar recursos no ensino fundamental de 7 a 14 anos, em detrimento dos jovens e adultos, e a transferência da liderança do Ministério da Educação em projetos educacionais, para outros ministérios, acabaram por promover um esvaziamento do direito de jovens e adultos à escolaridade básica.

Em 2000, ano da aprovação das Diretrizes Curriculares Nacionais para a Educação de Jovens e Adultos, o CESAS teve seu nome alterado para Centro de Educação de Jovens e Adultos da Asa Sul, mas manteve a sigla CESAS. Nesse ano houve, muito mais que apenas no nome, uma grande mudança na metodologia de ensino. O método supletivo com plantões de dúvidas, impessoal deu lugar à modalidade adequada a jovens e adultos, com aulas expositivas, possibilitando então ao estudante uma perspectiva mais rica, abrangente, humana e interativa dos conteúdos estudados.

A instituição atende aos três segmentos de EJA, nos três turnos, presencial, e também os $2^{\circ}$ e $3^{\circ}$ segmentos via EAD - Educação a Distância. O perfil do corpo discente, atualmente, é de adolescentes e de jovens que, em sua maioria, apresentaram insucesso na escola regular, jovens e adultos que exercem atividades na cadeia produtiva, desempregados, pessoas com necessidades educacionais especiais, trabalhadores dos diversos setores da economia, também donas de casa e auxiliares do lar. São residentes no Distrito Federal e na região do entorno, majoritariamente de baixa renda, com dificuldade de frequência diária à escola. Esses estudantes buscam a escola para fugir do desemprego ou na esperança de serem preparados para o mercado econômico de Brasília, estruturado sobre o serviço público, prestação de serviços ou comércio. Em todos os casos, o letramento é essencial, tanto para a aprovação em concursos públicos quanto para o desempenho das demais atividades.

No CESAS, também são atendidos quase 400 estudantes com necessidades educacionais especiais, matriculados regularmente e acompanhados pelas salas de recursos, nas quais se procura promover, de fato, a inclusão deles nas salas regulares.

A Biblioteca do CESAS foi rebatizada, em 1999, de Biblioteca Paulo Freire. É composta por um acervo de livros de literatura, dicionários, livros didáticos e enciclopédias; bem como por mesas para leitura e estudos, equipe de atendimento, sala para classificação bibliográfica e banheiros. Entretanto, não possui ambiente estimulante nem atrativo para leitura. 


\section{4- Justificativa e caracterização do problema}

A história recente do Brasil mostra que desde meados do século $X X$ houve substituição do modelo econômico, antes basicamente agrícola-comercial que se utilizava de mão-de-obra sem letramento ou qualificação específica, para um modelo urbano-industrial, mais exigente quanto à preparação da mão-de-obra, que agora deve estar apta à manipulação de equipamentos sofisticados e às sutilezas e rigores dos códigos da escrita. Inserida no modelo capitalista e sempre diante de novas necessidades, cabe à escola atual, seja Regular ou de EJA, não apenas preparar cidadãos para o trabalho, mas acima de tudo, promover uma formação que permita viver, compreender e transformar o seu meio. É na escola que primeiramente serão oferecidas "práticas de letramento: leitura de bons livros, filmes, obras de arte, entre outros, para que o estudante possa ter acesso a essas práticas e partilhar com igualdade de condições com um interlocutor letrado" (BORTONE, 2008, p.23).

Sendo assim, nos dias atuais, é preocupante a constatação, pela unanimidade de professores do CESAS, de que os estudantes da EJA em sala de aula, ou fora dela, apresentam domínio ainda precário da habilidade de leitura. Tanto os que já alcançaram o $3^{\circ}$ segmento, quanto os que já se encontram inseridos no mundo do trabalho, em que "tudo é mediado pela escrita" (GARCEZ, 2004, p.8), não dominam a leitura ou a escrita de forma autônoma e demonstram dificuldades, angústia e apatia quando solicitados a ler e escrever, de forma crítica, sobre determinado tema. Apesar de a comunidade escolar reconhecer o problema, não há na instituição, atualmente, um trabalho efetivo voltado para motivar e estimular os estudantes a lerem mais e melhorarem sua habilidade de ler e compreender textos.

Nossa cultura é escrita. Mesmo com o advento da televisão e do computador, nada foi feito até agora que substitua a palavra escrita como acesso ao acervo de conhecimentos acumulados pela humanidade durante séculos. Por isso, um dos principais objetivos da educação é desenvolver a capacidade de leitura dos estudantes, transformando-os efetivamente em leitores, pessoas que saibam ler criticamente qualquer texto, argumentando, discutindo e posicionando-se diante das ideias expostas. Na fala de Yunes (2008 p.1) "é possível estimular a prática da leitura para a formação de um indivíduo mais consciente de si, do outro e do seu papel na sociedade".

É consenso entre os professores de que um dos requisitos para a prática da escrita é a leitura. Segundo Garcez (2004, p.6), escrever bem é resultado de "muita prática, muita reflexão e muita leitura". Nesse sentido, o estímulo à leitura deve passar pela escola, o "lugar" oficial para o letramento, cabendo a ela transferir os conhecimentos adequados à conquista dessa habilidade e desenvolver programas e projetos que a incentive e estimule, 
dinamizando aulas ou oferecendo ambientes, recursos e acervos variados. Mais uma vez, Yunes alerta, entretanto, para a questão de que

\begin{abstract}
a leitura não é apenas assunto da escola, nem está atrelada a uma linguagem: ela pertence à vida social e está nos museus, nos centros culturais, na vida urbana como um todo - o letramento é a tradução da cultura em discurso - e deve ser incentivada sob todas as modalidades. Arrumar o pensamento ajuda a entender a 'escrita' do mundo e, no sentido inverso, o convívio com as linguagens que grafam o mundo pode dar melhores condições de 'uso' do pensamento, de 'compreensão' da leitura, fortalecendo (inter) subjetividades em formação. (trecho da entrevista à revista SESC-Rio, nov., 2008)
\end{abstract}

Seja qual for o ponto de partida de qualquer projeto de incentivo à leitura, o primeiro passo deverá ser a motivação, tanto de professores quanto de estudantes. A aquisição da prática e consequentemente o prazer da leitura não ocorre de modo espontâneo. É necessário um trabalho cujo objetivo deverá ser o de "despertar nos profissionais a consciência de que a leitura envolve saber e prazer" (COSSON, 2006, p. 53). Experiências realizadas nesse sentido mostraram que oficinas de criatividade com leituras variadas levaram os professores ligados ao trabalho na biblioteca a "descobrir que ler e escrever rimam com prazer e que a biblioteca escolar é muito mais do que o lugar onde se guardam os livros" (idem, p. 55).

Assim como ocorre em relação ao corpo docente, os estudantes precisam ser levados a perceber que a prática de leitura é um diferencial na vida estudantil e na sociedade, como cidadão. Nos últimos anos, a inserção no ensino da pedagogia de projetos também possui seus relatos sobre o sucesso de experiências bem-sucedidas em diversas áreas, especialmente no tocante à área de linguagens. Algumas dessas atividades também foram relatadas por Cosson:

\begin{abstract}
Crianças, adolescentes e adultos embarcam com mais entusiasmo nas propostas de motivação e, conseqüentemente, na leitura quando há uma moldura, uma situação que lhes permite interagir de modo criativo com as palavras. Ė como se a necessidade de imaginar uma solução para um problema ou de prever determinada ação os conectasse diretamente com o mundo da ficção e da poesia, abrindo portas e pavimentando caminhos para a experiência literária. (...) os estudantes reconheceram que não costumavam ler textos literários. Aliás, não liam livros em geral. O modo como thes havia sido introduzida a leitura, porém, permitira que descobrissem que gostavam de ler, que os livros faziam parte de suas vidas e que as escolas precisavam dos livros e dependia deles ajudar os professores que estavam nas salas de aula a fazer da leitura uma atividade de saber e prazer. Muitos saíram com planos para modificar as condições de leitura existentes em suas escolas. Muitos começaram a sonhar com uma verdadeira biblioteca. (COSSON, 2006, p. 55)
\end{abstract}

Como é possível perceber, o trabalho realizado com a leitura é um processo. O desenvolvimento do estudante, como leitor, exige tempo, dedicação e planejamento. Não basta pedir que o estudante leia ou que passe a gostar de ler. É preciso mostrar-lhe que ler é uma atividade enriquecedora e a principal arma que ele terá durante toda vida, para conhecer o mundo. Para isso, é necessário dar ao estudante a oportunidade de ter experiências gratificantes com a leitura. Outra autora que partilha dessa ideia é Costa, em que 
É importante orientar sobre o valor da leitura e a forma de desenvolvimento das atividades de leitura programadas para serem realizadas, em sala e em casa. Essa visão geral direcionará o comportamento do estudante para as diversas possibilidades de leitura; proporcionará segurança aos leitores menos aptos para a leitura, uma vez que não se sentirão desassistidos. (COSTA, 1991, p.15).

A escola deve dedicar-se a conquistar o estudante para a cultura, despertando nele a curiosidade intelectual. Esse processo pedagógico é uma espécie de sedução, em que o gosto pela leitura nasce do encanto, do prazer das descobertas, e não do fato de estar-se cumprindo uma obrigação escolar.

A necessidade de existir um elo, uma ponte entre o estudante e a biblioteca, ou ao espaço de leitura, que dê ao pretenso leitor razões para se aventurar mais, ler mais e diversamente, é suprida pela mediação. Sua importância aparece em Vygotsky (s/d, apud BORGES, 2002, p.134) ao mostrar que "a mediação [...] é o processo de intervenção de um elemento intermediário numa relação; a relação deixa, então de ser direta e passa a ser mediada por esse elemento" e acrescenta ainda que "é um processo essencial para tornar possível atividades psicológicas voluntárias, intencionais, controladas pelo próprio indivíduo". No que se refere aos métodos de incentivo à leitura, Yunes (2008, p.1) afirma que "é necessário encontrar um mediador apaixonado que leve o potencial leitor a se aventurar pela leitura, já que ler é uma excursão sobre a vida e o mundo que atravessa o tempo e o espaço". Assim, "se a escola é a instância mediadora da elevação cultural dos educandos [...] o professor deve ser o elemento mediador da cultura elaborada, de forma que os alunos dêem um salto na compreensão da realidade" (LUCKESI, 1991, p. 164-165).

Por acreditar que a formação da consciência critica dos cidadãos está inevitavelmente vinculada à aquisição da habilidade de leitura; por partilhar da visão de Ribeiro (1999) - na qual a compreensão de textos escritos tem implicações práticas muito significativas ao possibilitar a integração de padrões de comportamento e amplos valores; por visionar de forma pedagógica que a leitura crítica pode ser uma ferramenta de aquisição de conhecimento, autonomia e satisfação e, finalmente, por perceber a necessidade e responsabilidade que o professor tem de mediar todo esse processo, este projeto se dispõe a criar situações de aprendizagem que levem os estudantes do CESAS a buscar, de forma eficiente e prazerosa, os ambientes de leitura.

Nessa trajetória, é fundamental que a aquisição da habilidade da leitura crítica ultrapasse os muros da escola, promovendo o estudante em agente de sua comunidade. Para isso é importante que o projeto tenha também como objetivo integrar a Comunidade de Trabalho/Aprendizagem em Rede na Diversidade - CTARD, para constituir grupos permanentes de intervenção local, compartilhando, além dos textos, experiências, estratégias e metodologias enriquecedoras para as práticas de sala de aula, da escola e das lutas dentro do contexto da EJA no Distrito Federal. 


\section{5- Objetivos}

\section{1- Objetivo Geral}

Co-construir a formação de leitores críticos, autônomos e reflexivos na EJA.

\section{2- Objetivos específicos}

- Promover situações diárias de aprendizagem, favoráveis à leitura e à produção de textos, pelos estudantes, dentro de sala de aula;

- Tornar a Biblioteca um ambiente mais atrativo e estimulante para que o estudante desperte para a prática da leitura;

- Criar o Laboratório de Leitura dentro da Biblioteca;

- Inserir no PPP do CESAS uma meta de estímulo à leitura, com rotina de visitas freqüentes dos estudantes ao Laboratório de Leitura e/ou à Biblioteca;

- Integrar a comunidade do CESAS à Comunidade de Trabalho/Aprendizagem em Rede na Diversidade - CTARD. 


\section{6- Atividades/responsabilidades}

O presente projeto visa à pesquisa e à coleta de dados para interferência e modificação do ambiente escolar com o intuito de otimizar as atividades pedagógicas. $O$ professor será o pesquisador, e o ambiente, a sala de aula.

O grupo a ser pesquisado será composto por 60 estudantes do $3^{\circ}$ segmento da EJA do CESAS. Como instrumento para levantamento dos dados, será utilizado um questionário, com questões semiabertas e fechadas (Anexo 1).

Conforme aponta Costa (1991), o professor hoje tem consciência da importância da leitura para o desenvolvimento pessoal, intelectual e social do jovem. Não se aceita mais a ideia de se indicar um livro para leitura extraclasse, no início do bimestre, e só vir a "falar" sobre ele no final do bimestre por meio de um resumo, de uma ficha literária ou de um teste para nota. Essa leitura superficial, quando ocorre, jamais desenvolverá o gosto pela leitura, servirá apenas como castigo e como fator de distanciamento da leitura.

Com a intenção de promover situações diárias de aprendizagem, favoráveis à leitura e à produção de textos dentro de sala de aula, o projeto prevê $20 \%$ das aulas semanais, divididas em módulos temáticos, voltadas para os seguintes assuntos: cidadania, saúde do trabalhador, autoestima, diversidade (gênero, etnia, campo e ensino especial), mundo do trabalho e valores sociais, em que cada módulo possuiria um texto motivador, trocados a cada semestre. Após a leitura dos temas reflexivos, primeiramente pela professora, depois pelos estudantes, seguir-se-ia um debate e depois a produção progressiva de um texto.

Seriam destacados os pontos de interesse, elencados os tópicos numa chuva de ideias, para em seguida serem organizados em tópicos frasais para a formação de parágrafos. Esses parágrafos encadeados resultariam em um texto final, que seria revisado, periodicamente, para, ao final de cada módulo temático, ter-se um texto final.

Expandir a experiência lúdica e incentivar a consciência crítica de nossos estudantes, conduz o olhar destes, como agentes, para a comunidade em que mora e trabalha, cria a sede de ultrapassar pequenos textos e de se aventurar em livros que também Ihes informem e, dentro desse pertencimento, possibilita o contato mais profundo com a literatura universal.

Além da intervenção em sala de aula, ocorreria uma leitura livre de uma obra literária de escolha do estudante, fruto das visitas ao laboratório de leitura, espaço privilegiado dentro da biblioteca, criado para a fruição da leitura prazerosa.

Os textos motivadores terão como uma das principais fontes o sítio eletrônico dos fóruns de EJA do Brasil (www.forumeja.org.br) com o objetivo de integrar a Comunidade de Trabalho/Aprendizagem em Rede na Diversidade - CTARD, para constituir grupos permanentes de intervenção local, compartilhando textos e experiências, com o intuito de consolidar a transdisciplinaridade. A intenção é que a atuação em sala de aula, influenciada pela CTARD, seja alicerçada pelas leituras na biblioteca, posteriormente, haveria a 
divulgação dos resultados e o envolvimento dos demais professores no projeto, além da divulgação das experiências no sítio dos fóruns do Brasil, espaço de compartilhamento da modalidade.

Conforme apresentado no tópico 3, ambiente institucional, a Biblioteca Paulo Freire, atualmente, não possui ambiente convidativo para leitura. O lugar é pouco arejado abafado e extremamente quente. O teto é poroso e com frequente queda de sedimentos, conforme observação e avaliação dos usuários e servidores. Precisa de reformas urgentes. São necessárias também tanto uma atualização das mídias quanto uma transformação ambiental que o torne adequado à leitura, demandas que pretendemos sanar com este PIL que propõe, principalmente, a criação do "Laboratório de Leitura".

O Laboratório de Leitura (anexo 2) - espaço atrativo e estimulante para a prática de leitura, momento importante onde ocorre o diálogo leitor/escritor, mediado pelo texto - tem como conseqüência a construção de sentido entre leitor e texto, fundamental para que aconteça leitura eficiente. Seria um ambiente de seis metros quadrados com estrutura de conforto ergométrico para possibilitar uma aventura saudável no campo do conhecimento, contando com mobiliário adequado: sofás, poltronas, pufes, almofadas e tapete antialérgico. 


\section{7- Cronograma}

As atividades para o desenvolvimento do projeto seguirão o cronograma abaixo, conforme Quadro 1.

\begin{tabular}{|l|l|l|l|l|l|l|l|l|l|l|}
\hline \multicolumn{1}{|c|}{ Atividades - 2010 } & mar & abr & Maio & jun & jul & ago & set & out & nov & dez \\
\hline 1- Elaboração do PIL & $\mathbf{X}$ & $\mathbf{X}$ & $\mathbf{X}$ & $\mathbf{X}$ & - & & & & & \\
\hline 2- Aplicação do questionário & & & & & - & $\mathbf{X}$ & & & & \\
\hline 3- Desenvolvimento das aulas & & & & & - & $\mathbf{X}$ & $\mathbf{X}$ & $\mathbf{X}$ & $\mathbf{X}$ & $\mathbf{X}$ \\
\hline 4- Desenvolvimento do CTARD & & & & & - & $\mathbf{X}$ & $\mathbf{X}$ & $\mathbf{X}$ & $\mathbf{X}$ & $\mathbf{X}$ \\
\hline 5- Reformulação da Biblioteca & & & & & - & $\mathbf{X}$ & $\mathbf{X}$ & $\mathbf{X}$ & & \\
\hline 6- Montagem Laboratório leitura & & & & & - & & & & $\mathbf{X}$ & $\mathbf{X}$ \\
\hline
\end{tabular}

Quadro 1

\section{8- Parceiros}

A montagem do laboratório de leitura será fruto de uma campanha com amplo envolvimento da comunidade escolar; do governo, nas trocas de materiais entre as escolas e na renda do FNDE; da Embaixada do Uruguai, madrinha do CESAS; e de doações do comércio de Brasília. (Quadro 2) 


\section{9 - Orçamento}

O orçamento será relativo à campanha junto aos parceiros.

Precisamos prever verba para a reforma do teto da Biblioteca Paulo Freire e, especificamente, para o Laboratório de Leitura.

O orçamento do teto da biblioteca do CESAS seria de $R \$ 9.480,00$ (nove mil e quatrocentos e oitenta reais), pois seria feita a instalação de placas de revestimento em 150 metros quadrados de gesso cartonado.

O Laboratório de Leitura seria formado, primeiramente, com as divisórias, posteriormente, contaria também com isolamento sonoro. O valor das divisórias em um espaço de seis metros quadrado, somado a sofás, almofadas, pufe e um tapete de dois metros quadrados seria de $R \$ 1.900,00$ (mil e novecentos reais). Esses valores são baseados na média do comércio de Brasília colhidos em junho de 2010.

A verba mínima necessária para a empreitada é de $\mathrm{R} \$ 11.470,00$ (onze mil e quatrocentos e setenta reais), conforme Quadro 2.

\begin{tabular}{|l|c|r|}
\hline \multicolumn{1}{|c|}{ Atividades } & Parceiros/Fonte financiadora & \multicolumn{1}{c|}{ Custo } \\
\hline 1- Elaboração do PIL & Professoras - SCT/GDF- UnB/UAB (MEC) & $\mathbf{9 0 , 0 0}$ \\
\hline 2- Aplicação do questionário & Professoras & $\mathbf{5 0 , 0 0}$ \\
\hline 3- Desenvolvimento das aulas & Professoras & $\mathbf{5 0 , 0 0}$ \\
\hline 4- Desenvolvimento do CTARD & Professoras/Direção & -- \\
\hline 5- Reformulação da Biblioteca & Comunidade Escolar- GDF- Embaixada Uruguai & $\mathbf{9 . 4 8 0 , 0 0}$ \\
\hline 6- Montagem Laboratório Leitura & Comunidade Escolar- GDF- Embaixada Uruguai & $\mathbf{1 . 9 0 0 , 0 0}$ \\
\hline TOTAL & -- & $\mathbf{1 1 . 4 7 0 , 0 0}$ \\
\hline
\end{tabular}

Quadro 2 


\section{0- Acompanhamento e avaliação}

A avaliação sobre um projeto de leitura deve considerar a contribuição social a que esse tipo de ensino se presta, visto que insere o indivíduo na realidade histórica do seu país, na mídia impressa, nas literaturas clássica, contemporânea, cordel e demais manifestações escritas. Considera, ainda, a bagagem de origem do educando, que reúne o falar popular, a musicografia herdada e todo o registro formal e informal. Desse modo, oportuniza ao estudante conhecer a própria cultura e compará-la a outras, especialmente no caso da língua inglesa.

Nessa perspectiva, a avaliação não pode ser concebida como instrumento de classificação, reprovação ou punição do educando pelo seu desinteresse ou falta de empenho em relação à leitura. Deve, antes, ter o objetivo de verificar os avanços e dificuldades dos educandos para interferir no processo, ajustá-lo e melhorá-lo em direção às metas estabelecidas.

Para isso, foram elencados alguns critérios de acompanhamento e avaliação que serão utilizados ao longo do processo.

\section{1 - instrumento de acompanhamento}

Como instrumentos de acompanhamento serão adotados os seguintes procedimentos:

- aplicar o questionário criado para esse fim (anexo 1, p.22), semestralmente, com o objetivo de diagnosticar e acompanhar os avanços e a dificuldades encontradas no processo de mediação;

- promover exposições das produções de textos dos estudantes, com o intuito de interação e permuta de experiências e sensações;

- incentivar eventos culturais, a exemplo de saraus, envolvendo leitura, música e exposições de arte, criando espaços, inclusive, para a interdisciplinaridade.

- verificar se o quantitativo de empréstimos de livros, por estudante, aumentou à medida que o projeto avança, identificando o gênero do estudante que mais procura o Laboratório de Leitura;

- comparar produções textuais anteriores e posteriores ao projeto. 
10.2 - instrumento de avaliação

Como instrumentos de avaliação os professores avaliarão nos textos produzidos se os estudantes adquiriram as seguintes habilidades:

- reconhecer o tema principal ou o objetivo do autor ao escrever o texto;

- localizar informações explícitas em textos orais ou escritos;

- relacionar informações a conhecimento do cotidiano e/ou experiências e atitudes pessoais para estabelecer hipóteses sobre as informações apreendidas;

- elaborar posicionamentos críticos acerca da sua realidade histórica e social;

- defender pontos de vista, demonstrando consciência de seu papel social. 


\section{1- Referências}

BORGES, I. A. Educação e personalidade. São Paulo: Mackenzie, 2002

BORTONE, M. E. Competência interacional e gramatical. Brasília: UnB, 2008.

COSSON, R. Letramento literário: teoria e prática. São Paulo: Contexto, 2006.

COSTA, E. M. Leitura motivada e produção de texto. Brasília: APLP, 1991.

GARCEZ, L. H. do C. Técnica de redação: o que é preciso saber para bem escrever. São Paulo: Martins Fontes, 2004.

HADDAD, S; DI PIERRO, M. C. Escolarização de jovens e adultos. Revista Brasileira de Educação, São Paulo, n. 14, maio-ago. 2000.

LUCKESI, C. C. Filosofia da Educação. São Paulo: Cortez, 1991.

OLIVEIRA, R. B. Laboratório de Leitura, Brasília, 20 jun. 2010. Ilustração criada para o projeto Mediação na formação de leitores na EJA.

RIBEIRO, V. M. M. Alfabetismo e atitudes: pesquisa com jovens e adultos. Campinas:

Papirus, 2002.

SOUZA, A. M. de, FIORENTINI, Leda M. R. e RODRIGUES, M. A. M., organizadoras.

Educação superior a distância: Comunidade de Trabalho e Aprendizagem em Rede (CTAR).

Brasília: UnB, 2009.

YUNES, E. Educação Social: entrevista com Eliana Yunes. Revista SESC-Rio, novembro, 2008. Disponível em http://www.sescrio.org.br/main.asp?ViewID=\{4159B317-DAE2-44948B1D-5DE34DFBF2FF\} acesso em 20. jul. 2010. 


\section{Anexo 1}

\section{QUESTIONÁRIO PIL UnB/CESAS}

O presente questionário é parte integrante do Projeto de Intervenção Local do Curso de Especialização em Educação na Diversidade e Cidadania, com ênfase na Educação de Jovens e Adultos (EJA), da Universidade de Brasília. Seu principal objetivo é acompanhar o ambiente escolar e criar situações de aprendizagem favoráveis à formação de leitores(as) críticos(as) dentro da EJA.

Leia com atenção e responda todas as questões. Se você não tiver certeza, marque a alternativa que mais se parece com o que você pensa. Procure refletir sobre as dificuldades que você encontra para ler ou elaborar textos. Tente se lembrar deste último semestre, o que você está estudando.

Como você não precisa assinar o questionário, procure ser honesto(a) em suas respostas registrando o que realmente pensa. Sua colaboração é muito importante.

\section{Leia as questões abaixo e marque apenas uma alternativa.}

1. Você é do sexo?

( ) Feminino

( ) Masculino

2. Qual a sua naturalidade (cidade e estado)?

3. Qual é a sua idade?

\section{Você tem emprego?}
( ) Sim
( ) Não

5. Em caso afirmativo, em que você trabalha?

\section{Você tem carteira assinada?}
( ) Sim
( ) Não 
7. A escola onde você estuda (CESAS) fica perto:

( ) da sua casa

( ) do seu trabalho

8. Você tem acesso à internet:

( ) somente em casa

( ) somente no trabalho

( ) em casa e no trabalho

( ) em nenhum destes lugares

9. Você possui endereço de correio eletrônico (e-mail)?

( ) Sim

( ) Não

10. Qual a maior dificuldade que você enfrenta para estudar?

( ) Chegar cansado e ainda tem que ir à escola

( ) O transporte urbano

( ) Não ter com quem deixar os filhos

( ) Outros. Qual(is)?

11. Qual a sua jornada de trabalho?

( ) 4 (quatro) horas diárias

( ) 6 (seis) horas diárias

( ) 8 (oito) horas diárias

( ) mais de 8 (oito) horas diárias.

12. Você trabalha regularmente aos sábados e domingos?
( ) Sim
( ) Não

13. Quanto tempo, por dia, você dedica à leitura?

( ) Menos de uma hora

( ) Mais de uma hora

14. Quantos livros você leu nos últimos três meses?
( ) Nenhum
( ) Quase um
( ) Um
( ) Dois
( ) Mais de dois 
15. Qual tem sido a finalidade da sua leitura?

( ) Trabalhos escolares

( ) Obter informações no trabalho (emprego)

( ) Adquirir mais conhecimento

( ) Obrigação

( ) Prazer/diversão

( ) Escrever melhor

16. Em qual ambiente você se sente mais à vontade para ler?

( ) Em sala de aula

( ) Em casa

( ) No ônibus

( ) Na Biblioteca do CESAS

( ) Em ambiente externo (parques e jardins)

17. Você acredita que a leitura ajuda a escrever bem?
( ) Sim
( ) Não

18. Em quais destas situações mais gosta de escrever?
( ) Redações ou textos pedidos na escola
( ) Cartas ou e-mails para os amigos ou parentes
( ) Textos ou documentos no trabalho

19. Entre os materiais escritos abaixo relacionados, marque 2 (dois) dos que você mais leu até hoje:
( ) gibi
( ) a Bíblia Sagrada
( ) revistas
( ) jornais
( ) livros de romance
( ) apostilas da escola

20. Atualmente, o que você mais tem lido? 


\section{Anexo 2 -}

llustração 1

\section{Laboratório de Leitura}

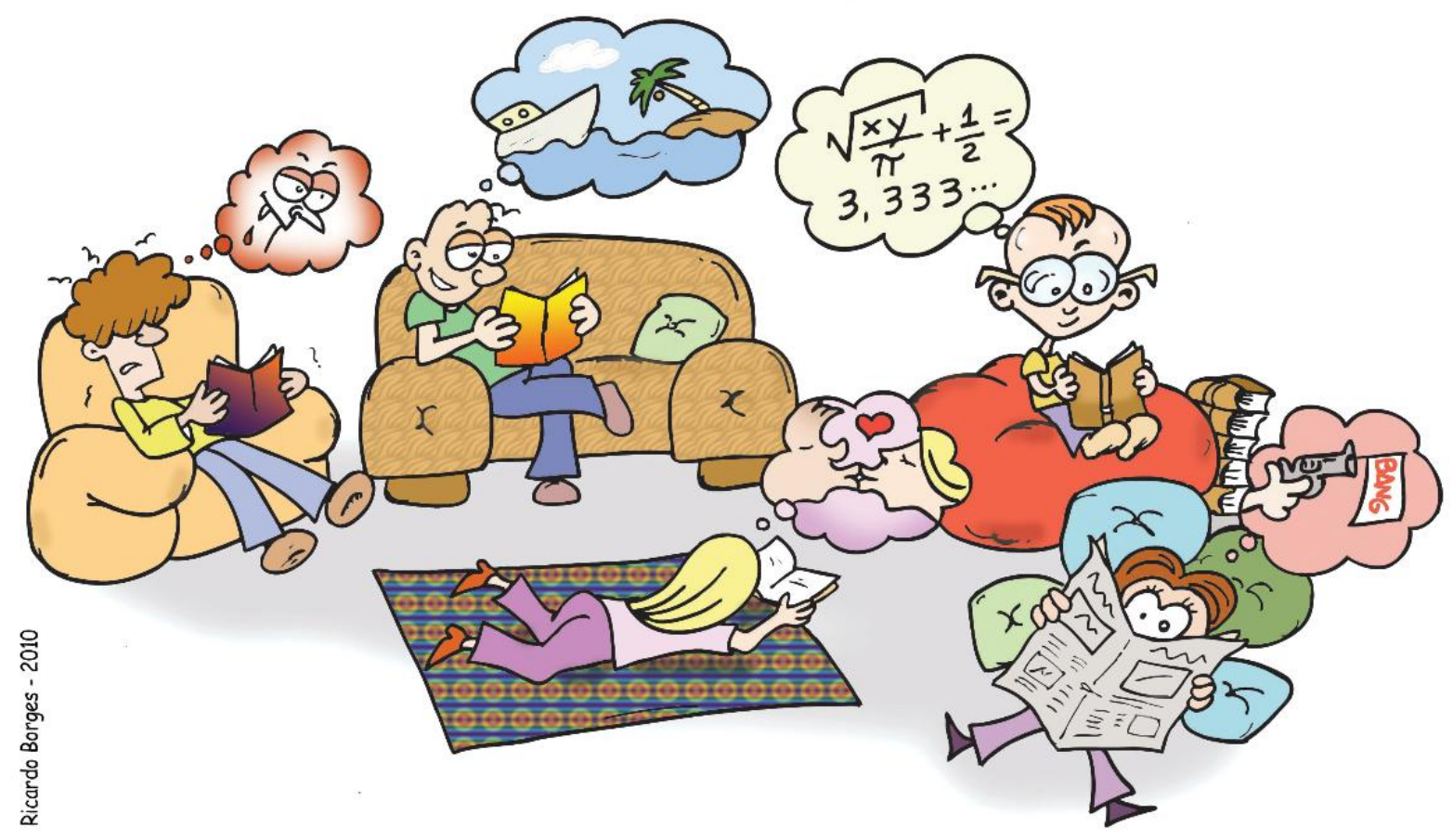

